\title{
Creation of the Standing Committee for Gender Equality in Science
}

Maria J. Esteban (CNRS and Université Paris-Dauphine, France)

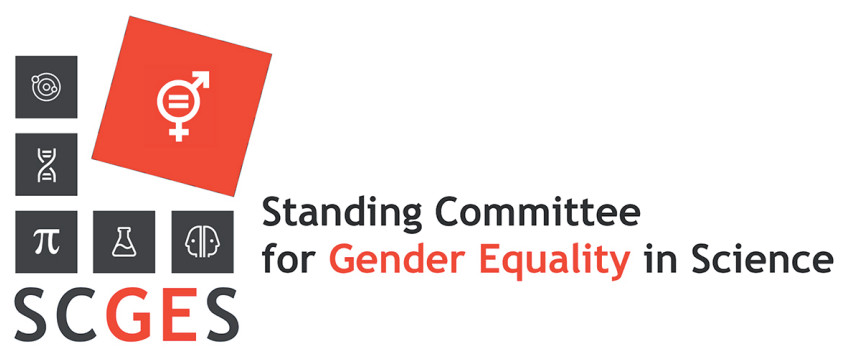

Some years ago, the International Council for Scientific Unions (ICSU) launched a call concerning the gender gap in science, to understand and measure it and to propose solutions to reduce it. Several members of ICSU, among them the International Mathematical Union (IMU) and the International Council for Industrial and Applied Mathematics (ICIAM) answered the call. The project was called 'A Global Approach to the Gender Gap in Mathematical, Computing and Natural Sciences: How to Measure It, How to Reduce It', and it was supported first by ICSU and then by the International Science Council (ISC), the result of a merger between ICSU and the International Social Science Council (ISSC).

A number of international unions and councils which took part in the project, and among them ICIAM and IMU, wished to act together to further promote gender equality in science by continuing and enlarging the work accomplished by that project and, in particular, by supporting women's and girls' equal access to science education and fostering equal opportunity and treatment for females in their careers. For this purpose, they have acted as founding partners for the establishment of a Standing Committee for Gender Equality in Science (SCGES). The founders are:

- International Astronomical Union (IAU)

- International Council of Industrial and Applied Mathematics (ICIAM)

- International Mathematical Union (IMU)

- International Union of Biological Sciences (IUBS)

- International Union of History and Philosophy of Science and Technology (IUHPST)

- International Union of Pure and Applied Chemistry (IUPAC)

- International Union of Pure and Applied Physics (IUPAP)

- Association for Computing Machinery (ACM)

- Gender in Science, Innovation, Technology and Engineering (GenderInSITE)

Further international organisations may join later as partners.

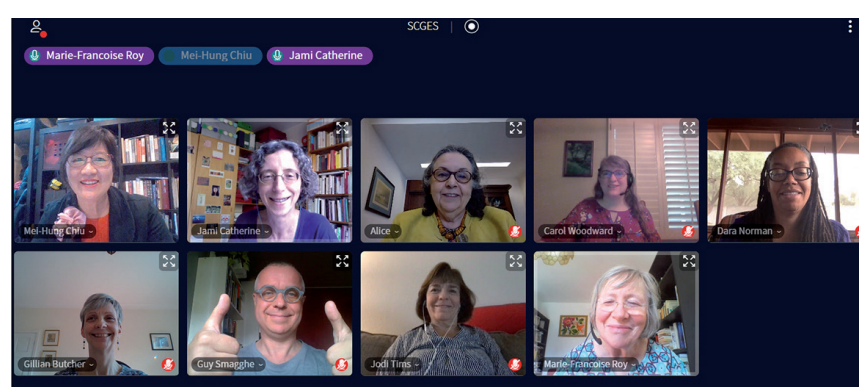

Among other things, the members of this Standing Committee are supposed to:

- Endeavor to promote gender equality in their own structure, proceedings and scientific discipline, noting the recommendations of the Gender Gap in Science Project.

- Share with SCGES, and especially with its chair, all relevant information that can help promote gender equality in science.

- Within the limits of its capacity, set up projects and initiatives to promote gender equality in science; for this purpose they may seek cooperation with other members of the Standing Committee.

- Decide whether to contribute to projects and initiatives led by other partners and endorsed by the SCGES, and consider the modalities of this contribution.

- Share communication relevant to gender equality in science with its members and through its networks by all means at its disposal, including social network accounts, website, newsletters and journals, electronic and in print.

- Call upon its member organisations or its representatives, if relevant, to set up national or regional initiatives to promote gender equality in science.

The committee was founded only recently and has only met for the first time in September 2020. Its newly created website can be found at the following address: https://gender-equality-in-science.org/

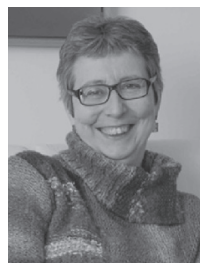

Maria J. Esteban is a CNRS senior researcher at Université Paris-Dauphine. Specialist in nonlinear PDEs and Mathematical Physics, she has been President of SMAI and ICIAM, and currently she is one of the ICIAM Officers as Past-President. More information about her activities and her CV can be found at her webpage https://www.ceremade.dauphine.fr/ esteban/MJEpage-engl.html. 